\title{
Histone tail cleavage as a novel epigenetic regulatory mechanism for gene expression
}

\author{
Sun-Ju Yi \& Kyunghwan Kim * \\ School of Biological Sciences, College of Natural Sciences, Chungbuk National University, Cheongju 28644, Korea
}

\begin{abstract}
Chromatin is an intelligent building block that can express either external or internal needs through structural changes. To date, three methods to change chromatin structure and regulate gene expression have been well-documented: histone modification, histone exchange, and ATP-dependent chromatin remodeling. Recently, a growing body of literature has suggested that histone tail cleavage is related to various cellular processes including stem cell differentiation, osteoclast differentiation, granulocyte differentiation, mammary gland differentiation, viral infection, aging, and yeast sporulation. Although the underlying mechanisms suggesting how histone cleavage affects gene expression in view of chromatin structure are only beginning to be understood, it is clear that this process is a novel transcriptional epigenetic mechanism involving chromatin dynamics. In this review, we describe the functional properties of the known histone tail cleavage with its proteolytic enzymes, discuss how histone cleavage impacts gene expression, and present future directions for this area of study. [BMB Reports 2018; 51(5): 211-218]
\end{abstract}

\section{INTRODUCTION}

In eukaryotic cells, the genomic DNA is packed in the nucleus via its compaction into chromatin. The fundamental unit of chromatin is called the nucleosome, in which approximately 147 base pairs of DNA are wrapped around an octamer of core histone. Histones are highly conserved basic proteins found in eukaryotes and even in some archaea (1-6). They are divided into five major families: $\mathrm{H} 1, \mathrm{H} 2 \mathrm{~A}, \mathrm{H} 2 \mathrm{~B}, \mathrm{H} 3$, and $\mathrm{H} 4$. Two copies of $\mathrm{H} 2 \mathrm{~A}, \mathrm{H} 2 \mathrm{~B}, \mathrm{H} 3$, and $\mathrm{H} 4$ histones form the core histone octamer, while the linker histone $\mathrm{H} 1$ binds to the nucleosome at the site where internucleosomal DNA enters and exits, further contributing to the structural and functional

*Corresponding author. Tel: +82-43-261-2292; Fax: +82-43-2602298; E-mail: kyungkim@chungbuk.ac.kr

https://doi.org/10.5483/BMBRep.2018.51.5.053

Received 19 February 2018

Keywords: Chromatin, Gene expression, Histone cleavage, Histone modification flexibility of chromatin $(5,7,8)$.

Chromatin is a dynamic structure, existing either as heterochromatin or euchromatin. Heterochromatin is more compact and transcriptionally inactive since genes are not easily accessible by transcription machinery proteins. In contrast, euchromatin is a decondensed type of chromatin and is transcriptionally active $(3,9)$. To allow transcription machinery proteins access to compacted DNA, a process known as chromatin remodeling reorganizes the chromatin structure to expose or hide regions of DNA for transcriptional regulation (10). It has been reported that chromatin remodeling occurs in several ways including histone modifications, exchange of histone variants, and ATPdependent chromatin remodeling (11).

The core histones contain two common domains: histone folding and histone tail. The $\mathrm{N}$-terminal tail of all four core histones and the C-terminal tail of $\mathrm{H} 2 \mathrm{~A}$ and $\mathrm{H} 2 \mathrm{~B}$ protrude outside the nucleosome, which undergoes a variety of posttranslational modifications (PTMs) including methylation, acetylation, propionylation, butylation, crontonylation, 2-hydroxyisobutylation, malonylation, succinylation, formylation, ubiquitination, citrullination, phosphorylation, O-GlcNAcylation, and ADP ribosylation (12-22). Functional outcomes of these histone modifications have been investigated. A well-established hypothesis suggests that histone modification may lead to alteration of contacts between different histones in adjacent nucleosomes or the interaction of histones with DNA. Notably, acetylation neutralizes the positive charge of the lysine and weakens the interaction between histone and DNA, resulting in loosening the chromatin structure $(13,23)$. Another well-characterized hypothesis of histone modification is that distinct patterns of histone modifications, or "histone codes", provide signals for the recruitment of specific non-histone protein complexes including transcription factors or proteins that modify the chromatin structure $(18,24,25)$. Diverse histone modifications within the chromatin act in a coordinated and orderly fashion to regulate gene transcription (26). The precise alteration of chromatin histone modification is regulated by both the chemical and physical changes of core histones. A typical mechanism of chemical modification is the selective enzymatic addition and elimination of specific histone modifications by histone-modifying enzymes ("writers" and

ISSN: 1976-670X (electronic edition)

Copyright (c) 2018 by the The Korean Society for Biochemistry and Molecular Biology

(c) This is an open-access article distributed under the terms of the Creative Commons Attribution Non-Commercial License (http://creativecommons.org/licenses/by-nc/4.0) which permits unrestricted non-commercial use, distribution, and reproduction in any medium, provided the original work is properly cited. 
"eraser"), which is a reversible chemical change $(27,28)$. A more extreme mechanism utilizes physical changes of nucleosome so that the ATP-dependent chromatin remodeler catalyzes the exchange of canonical histones with histone variants, resulting in the removal of all pre-existing PTMs (29). An intermediate mechanism between these two mechanisms is the regulated proteolysis of histone tail, which physically and irreversibly removes pre-existing multiple PTMs (30-33).

In contrast to histone modification or histone exchange, the mechanism and the biological role of histone tail cleavage have not been fully understood. Although the presence of a proteolytic enzyme in histone preparations of calf thymus was observed in 1959 (34), and truncated histones were found in calf thymus and Tetrahymena in 1970s $(35,36)$, few publications were reported until the early 2000s. However, the regulated cleavage of histone has become an active and interesting topic of epigenetic regulation since the late 2000s. Various enzymes responsible for histone clipping and the biological significance associated with histone cleavage have been studied as shown in Table 1. We discuss the identified enzymes, the regulation, and the biological significance of histone cleavage. Moreover, we propose putative mechanisms that suggest how histone cleavage modulates gene expression.

\section{HISTONE H2A AND H2B CLEAVAGE}

In 1976, a protease associated with purified calf thymus chromatin was found to act specifically upon histone $\mathrm{H} 2 \mathrm{~A}$, yielding a C-terminal truncated $\mathrm{H} 2 \mathrm{~A}$. This fragment was derived from the removal of fifteen amino acids from the C-terminal H2A, of which Val114 was the new C-terminal residue (36). The responsible enzyme was further investigated and named the $\mathrm{H} 2 \mathrm{~A}$ specific protease $(\mathrm{H} 2 \mathrm{Asp})(37,38)$. The truncation of $\mathrm{H} 2 \mathrm{~A}$ was also observed in both myeloid and lymphatic leukemia cells (39-41) and retinoic acid-induced differentiation of THP-1 promonocytes into macrophages (42, 43). Later, it was argued that H2Asp might be neutrophil elastase (44). Neutrophil elastase is a neutrophil-specific protease required for neutrophil extracellular trap (NET) formation. It has been reported that, upon reactive oxygen

Table 1. List of histone proteases identified and their roles

\begin{tabular}{|c|c|c|c|c|c|}
\hline Histone & Protease & Cleavage site(s) & Model & $\begin{array}{l}\text { Biological significance of } \\
\text { activity }\end{array}$ & Reference \\
\hline \multirow[t]{3}{*}{$\mathrm{H} 2 \mathrm{~A}$} & $\begin{array}{l}\text { Histone } \mathrm{H} 2 \mathrm{~A} \text { specific } \\
\text { protease }(\mathrm{H} 2 \mathrm{Asp})\end{array}$ & Asn90-Asp91 & Chicken liver extract & $?$ & 47 \\
\hline & Neutrophil Elastase & Val114-Leu115 & Neutrophil & $\begin{array}{l}\text { NET (neutrophil extracellular } \\
\text { trap) formation }\end{array}$ & 44 \\
\hline & $\mathrm{H} 2 \mathrm{~A}$ protease & Val114-Leu115 & Calf thymus & $?$ & 38 \\
\hline $\mathrm{H} 2 \mathrm{~B}$ & Tryptase & $?$ & Mouse mast cells & Mast cell differentiation & 48,49 \\
\hline \multirow[t]{11}{*}{$\mathrm{H} 3$} & MMP-9 & Lys18-Gln19 & Bone marrow macrophages & Osteoclastogenesis & 53 \\
\hline & Cathepsin L & $\begin{array}{l}\text { Ala21-Thr22, Thr22-Lys23, } \\
\text { Lys23-Ala24 Ala24-Ala25, } \\
\text { Arg26-Lys27, Lys27-Ser28 }\end{array}$ & Mouse ESCs & ESC differentiation & 51 \\
\hline & Human ESC protease & $\begin{array}{l}\text { Ala21-Thr22, Arg26-Lys27, } \\
\text { Ala31-Thr32 }\end{array}$ & Human ESCs & ESC differentiation & 50 \\
\hline & $\begin{array}{l}\text { Glutamate } \\
\text { dehydrogenase }\end{array}$ & Lys23-Ala24, Lys27-Ser28 & Chicken liver extracts & ? & 58 \\
\hline & Yeast endopeptidase & Ala21-Thr22 & S. cerevisiae & $\begin{array}{l}\text { Induced under nutrient } \\
\text { deprivation and sporulation }\end{array}$ & 55 \\
\hline & $\begin{array}{l}\text { Vacuolar protease B } \\
\text { (Prb1) }\end{array}$ & Lys23-Ala24 & S. cerevisiae & $?$ & 69 \\
\hline & $\begin{array}{l}\text { Foot-and-mouth disease } \\
\text { virus 3C protease } \\
\text { (FMDV 3C protease) }\end{array}$ & Leu20-Ala21 & Infected BHK-21 cells & $\begin{array}{l}\text { Host cell transcription shut } \\
\text { off }\end{array}$ & 61 \\
\hline & JMJD5 & Lys9-Ser10 & Lung cancer cells & Induced under DNA damage & 56 \\
\hline & $?$ & ? & Tetrahymena micronuclei & $?$ & 60 \\
\hline & Cathepsin D & Lys23-Ala24 & Mouse mammary gland & Involution mammary gland & 71 \\
\hline & Tryptase & & Mouse mast cells & Mast cell differentiation & 48,49 \\
\hline $\mathrm{H} 4$ & Granzyme A & $?$ & B-lymphoid & $\begin{array}{l}\text { Staurosporine-induced cell } \\
\text { death }\end{array}$ & 76 \\
\hline Histone $\mathrm{H} 1$ & $?$ & $\begin{array}{l}\text { H1 processed into three } \\
\text { different components }(\alpha, \beta, \gamma) \text {. }\end{array}$ & Tetrahymena micronuclei & Cell division & 75 \\
\hline
\end{tabular}


species production, the neutrophil elastase translocates from azurophilic granules into the nucleus and degrades specific histones, leading to chromatin decondensation (45). However, the biological significance of the C-terminal clipped $\mathrm{H} 2 \mathrm{~A}$ in NET formation remains unclear.

Volger et al. showed that cells expressing C-terminally truncated $\mathrm{H} 2 \mathrm{~A}$ (amino acids 1-114) were vulnerable to cellular stress, implying a pivotal role of this tail in cellular homeostasis (46). They then demonstrated that the $\mathrm{H} 2 \mathrm{~A}$ C-terminal tail is important in nucleosome stability and mobility in vivo and in vitro. Furthermore, they showed that this C-terminal $\mathrm{H} 2 \mathrm{~A}$ tail is implicated in regulating chromatin remodeling process by ISWI-type remodelers and functions as a recognition module for histone $\mathrm{H} 1$. These results suggest that H2A C-terminal tail (amino acids 115-129) stabilizes the nucleosomal core particle, while mediating the protein interactions regulating chromatin dynamics.

In 1993, a second H2A specific protease was found in a chicken liver nuclear extract (47). It was argued that by using a protease inhibition assay, this $\mathrm{H} 2 \mathrm{Asp}$ is an aspartic acid-like protease. The $\mathrm{H} 2 \mathrm{Asp}$ generated a single clipped $\mathrm{H} 2 \mathrm{~A}$ product (H2AGlu91) in the in vitro cleavage assay. Interestingly, it was found that the expression and the activity of H2Asp were only detected in liver nuclear extract (tissue-specific). However, the function of the C-terminal deleted $\mathrm{H} 2 \mathrm{~A}$ and the characterization of the responsible protease remains elusive.

Recently, an enzyme for an $\mathrm{H} 2 \mathrm{~B}$ tail cleavage was reported by Pejler et al. They demonstrated that tryptase clipped off the $\mathrm{N}$-terminal tails of histone $\mathrm{H} 2 \mathrm{~B}$ as well as histone $\mathrm{H} 3(48,49)$. Mast cells contain a high content of cytoplasmic secretory granules densely packed with bioactive substances, including a mast cell specific protease, tryptase, which performs pro-inflammatory functions. Unexpectedly, they revealed that the tryptase relocalizes from granules into the nucleus during the cell death process and cleaves core histones. The tryptase-dependent truncation of Histone $\mathrm{H} 2 \mathrm{~B}$ and $\mathrm{H} 3$ also occurred in mast cell differentiation. They also found that the tryptase is mostly localized to the heterochromatin, and chromatin fraction from tryptase deficient cells is more resistant to micrococcal nuclease than that from wild type. This implies that tryptase may control the chromatin structure by promoting the formation of euchromatin over heterochromatin. In their subsequent study (49), however, they demonstrated that the absence of tryptase leads to the age-dependent accumulation of $\mathrm{H} 2 \mathrm{BK} 5 \mathrm{ac}$, which was associated with an extensive upregulation of markers of non-mast cell lineages. These results suggest that tryptase can positively or negatively modulate gene expression depending on the chromatin state of the mast cells.

\section{HISTONE H3 CLEAVAGE}

The clipping of Histone $\mathrm{H} 3$ has been investigated more intensively than that of other histones. Histone $\mathrm{H} 3$ has numerous sites that are susceptible to several proteases (33) and the $\mathrm{N}$-terminal cleavage of $\mathrm{H} 3$ has been reported in many cellular processes, including mouse embryonic stem cell (ESC) differentiation, viral infection, aging, yeast sporulation, senescence, DNA damaging stress, and osteoclastogenesis (50-56). Additionally, $\mathrm{H} 3$ protease activity has been found in Tetrahymena micronuclei, avian liver tissues, human ESCs, and mouse mast cells $(48,54,57-59)$.

In 1980, Allis et al. reported that micronuclei of Tetrahymena contained two electrophoretically distinct forms of histone $\mathrm{H} 3$; the fast migrating form $\left(\mathrm{H}^{\mathrm{F}}\right)$ and the slow migrating form $\left(\mathrm{H} 3^{\mathrm{S}}\right)$. The fast migrating form, $\mathrm{H} 3^{\mathrm{F}}$ was derived from $\mathrm{H} 3{ }^{\mathrm{S}}$ by a physiologically regulated, proteolytic processing event in the condition of cell growth and/or division, but not in non-growth and starvation, indicating that $\mathrm{H} 3$ proteolytic cleavage may occur regularly each generation at a specific point in the cell cycle (60).

Several studies have shown the effect of viral infection on the integrity of histones. It was reported that infection of BHK cells with foot-and-mouth disease virus (FMDV) caused the loss of histone $\mathrm{H} 3$ and the simultaneous formation of a new chromatin-associate protein (Pi) which migrates between histones $\mathrm{H} 2 \mathrm{~A}$ and $\mathrm{H} 4$ on SDS-polyacrylamide gels (52). Subsequently, Falk et al. showed that $\mathrm{Pi}$ is the truncated $\mathrm{H} 3$ form lacking the $20 \mathrm{~N}$-terminal residues by proteolytic cleavage during infection (61). Also, they found that the transition of histone $\mathrm{H} 3$ into $\mathrm{Pi}$ was catalyzed by the FMDV $3 \mathrm{C}$ protease, which had been known to be related in the proteolytic processing of the viral polyprotein into the mature gene products. Another group reported that FMDV protease $3 C$ inhibits gene transcription and its inhibitory mechanism might involve the truncation of histone $\mathrm{H} 3$ (62). These results suggested that the FMDV virus controls the host cell's transcription by modulating histone $\mathrm{H} 3 \mathrm{~N}$-terminal cleavage.

Cathepsin L, a lysosomal protease, is a member of the papain-like super family of cysteine protease. Cathepsin L plays an important role in extracellular matrix degradation related to cancer, bone remodeling, and cardiovascular disease, and functions as an immune modulator via the generation of peptide antigens for $\mathrm{MHC}$ class II presentation $(63,64)$. Although Cathepsin L is mainly localized within lysosome, it is also found in the nucleus, and the functions of Cathepsin L in the nucleus have been reported (65-68). In 2008, Duncan et al. demonstrated that Cathepsin L proteolytically processes histone $\mathrm{H} 3$ during mouse ESC differentiation (51), in the first report presenting the implication of histone cleavage in the alteration of epigenetic signatures upon differentiation. Histone $\mathrm{H} 3$ was cleaved at the $\mathrm{N}$-terminal tail during ESC differentiation, with alanine 21 being the primary site of cleavage, while Cathepsin $\mathrm{L}$ was identified as a protease responsible for $\mathrm{H} 3 \mathrm{~N}$-terminal tail clipping. They also suggested that this cleavage activity might be modulated by covalent modifications such as H3K18ac or H3K27me2 via in vitro cleavage assays. Moreover, this 
removal of histone $\mathrm{H} 3 \mathrm{~N}$-terminal tail inhibited the ability of $\mathrm{CBX} 27$ to bind to $\mathrm{H} 3 \mathrm{~K} 27$ methylation, indicating the histone H3 cleavage by Cathepsin L could lead to significant downstream effects. The biological significances of the Cathepsin L-mediated H3 cleavage during ESC differentiation remain elusive.

The proteolytic processing of histone $\mathrm{H} 3$ tail by Cathepsin $\mathrm{L}$ was also observed in models of oncogene-induced and replicative senescence (50). It was found that unlike ESC differentiation, H3.3 is preferentially cleaved over H3.1 during cellular senescence. RNA-sequencing studies revealed that the overexpression of the cleaved H3.3 in fibroblasts results in transcriptional downregulation of cell cycle genes, with significant overlap of genes that lose $\mathrm{H} 3 \mathrm{~K} 4 \mathrm{me} 3$ during cellular senescence. It was suggested that $\mathrm{H} 3.3$ tail cleavage plays a key role in silencing the transcription of cell cycle-promoting genes by removing $\mathrm{H} 3 \mathrm{~K} 4 \mathrm{me} 3$.

In 2009, Santos-Rosa et al. used a yeast model and detected the endopeptidase activity of nuclei preparations toward histone $\mathrm{H} 3$, which was low in cells growing exponentially but increased in cells grown into stationary phase or shifted to sporulation (55). They found that the $\mathrm{H} 3$ endopeptidase is a serine protease clipping histone $\mathrm{H} 3$ after alanine 21, but were unable to further define a specific protease among the 24 serine proteases of $S$. cerevisiae. They also showed that loss of the $\mathrm{H} 3 \mathrm{~N}$-terminal tail correlates with the induction of gene expression that precedes $\mathrm{H} 3$ displacement. To test if the $\mathrm{H} 3$ tail-cleavage is prerequisite for gene induction, Santos-Rosa et al. used a yeast strain having the mutation in the histone $\mathrm{H} 3$ cleavage site which is unable to cleave the $\mathrm{H} 3$ tail. This mutant showed impaired expression of genes activated on the stationary phase and sporulation, indicating that the cleavage of the $\mathrm{H} 3$ tail at gene promoters contributes to the proper induction of gene expression. After 5 years, it was reported the vacuolar proteinase B (Prb1) has a cleavage activity toward histone $\mathrm{H} 3 \mathrm{~N}$-terminus in both whole cell extracts and nuclear extracts of $S$. cerevisiae. They demonstrated that the purified Prb1 can cleave the $\mathrm{H} 3 \mathrm{~N}$ terminus between Lys23 and Ala24 in vitro (69).

Mandal et al. reported that a cysteine protease activity in chicken liver is specific for histone $\mathrm{H} 3$ (57). Later, they revealed via mass spectrometric analysis that this protease is glutamate dehydrogenase (58). Glutamate dehydrogenase was found to bind to four core histones but cleaving only the histone $\mathrm{H} 3$ tail in its free and chromatin context. Additionally, the truncation of $\mathrm{H} 3$ was observed in quail liver during the aging process, although the responsible enzyme was not identified $(54,70)$.

In the involuting mammary gland, the nuclear translocation of Cathepsin D caused the proteolytic cleavage of $\mathrm{H} 3$ at its amino terminal tail (71). They showed that $\mathrm{H} 3$ was preferentially cleaved by Cathepsin D between lysine 23 and alanine 24. Interestingly, they found that the nuclear translocation of Cathepsin D was mediated by its post- translational modification, tyrosine nitration.

Recently, our group found that matrix metalloproteinase 9 (MMP-9) is the principal protease of the histone $\mathrm{H} 3 \mathrm{~N}$-terminal tail during osteoclast differentiation (53). It has been shown that MMPs are a family of zinc-dependent endopeptidases that remodel the pericellular space primarily through the cleavage of extracellular matrix proteins. Although MMP-9 was known as a secretory protein, we detected the nuclear accumulation of MMP-9 during osteoclastogenesis through biochemical studies (74). We found that MMP-9 specifically cleaved H3K18-Q19 in vitro and in vivo. Furthermore, our results also showed that MMP-9 enzymatic activity toward $\mathrm{H} 3 \mathrm{~N}$-terminal tail is significantly facilitated by $\mathrm{H} 3 \mathrm{~K} 18$ acetylation and that p300/CBP is the histone acetyl transferases responsible for H3K18ac observed in osteoclast cells. Importantly, our findings indicated that MMP-9 was necessary for $\mathrm{H} 3$ tail cleavage near transcription start sites or gene bodies of a set of osteoclastogenic genes and concurrent gene activation during osteoclast differentiation, suggesting that $\mathrm{H} 3 \mathrm{~N}$-terminal proteolysis induces gene activation.

Shen et al. demonstrated that JMJD5 mediates histone H3 $\mathrm{N}$-tail proteolytic cleavage at the carboxyl side of $\mathrm{H} 3 \mathrm{~K} 9 \mathrm{me} 1$ under stress conditions such as a DNA damage response (56). JMJD5, a Jumonji C (JmjC) domain-containing protein, was originally known as histone $\mathrm{H} 3$ lysine 36 dimethylation (H3K36me2), responsible for gene expression. In A549 cells, under cell stress conditions, JMJD5 bound to gene promoters and cleaved H3K9me1, suggesting JMJD5-mediated histone cleavage may be responsible for gene transcription regulation.

As previously mentioned, mast cell tryptase functioned as a clippase of histone $\mathrm{H} 3$ as well as $\mathrm{H} 2 \mathrm{~B}$ and, in aging mast cells, the partial loss of tryptase expression was accompanied by a decrease of $\mathrm{H} 3$ and $\mathrm{H} 2 \mathrm{~B}$ clipping $(48,49)$. While tryptasedeficiency did not affect the posttranslational modifications of histone $\mathrm{H} 3$, it caused an increase of $\mathrm{H} 2 \mathrm{BK} 5 \mathrm{ac}$. Therefore, the biological significance of histone $\mathrm{H} 3$ clipping in mast cells still needs to be determined.

\section{OTHER HISTONES CLEAVAGE}

A limited number of studies have reported the conversion of histone $\mathrm{H} 1$ or $\mathrm{H} 4$ into a smaller form via a regulated proteolysis. Nevertheless, the degradation of histone $\mathrm{H} 1$ or $\mathrm{H} 4$ has been shown in several biological processes including the macronuclear degradation of Tetrahymena and staurosporineinduced cell death (75-77). Interestingly, it was shown that histone $\mathrm{H} 1$ of Tetrahymena micronuclei was processed into smaller forms. Tetrahymena contains two different nuclei: a macronucleus and a micronucleus. Micronucleus-specific histone $\mathrm{H} 1$ differs from macronuclear $\mathrm{H} 1$. Micronucleusspecific histone $\mathrm{H} 1$ was larger and is proteolytically processed into different components $(\alpha, \beta, \gamma$ and $\delta)$. This proteolytic processing of $\mathrm{H} 1$ histone was regulated in the pathway of micronuclear differentiation (75). Lee et al. demonstrated that 
histone $\mathrm{H} 4$ is cleaved by granzyme $\mathrm{A}$ under apoptotic process in B-lymphocytes (76). Granzyme A is a serine protease in the cytotoxic granules found in natural killer cells and cytotoxic $\mathrm{T}$ cells. They suggested that Granzyme A-mediated $\mathrm{H} 4$ tail cleavage contributes to the disintegration of the chromatin architecture during the cell death process (76).

\section{EPIGENETIC REGULATORY MECHANISM BY HISTONE CLEAVAGE}

The proteolytic cleavage of histone is an interesting and active topic of epigenetic modifications. Despite the increasing number of studies that demonstrate novel enzymes and cellular processes related to histone cleavages, the mechanism by which cleaved histones regulate gene expressions still needs to be explained. Here, we discuss recent findings, focusing on how histone cleavage impacts gene expression (Fig. 1).

\section{Influence on chromatin compaction}

Eukaryotic DNA is packed into chromatin, which enables the genomic DNA to fit in the limited space of the nucleus. However, chromatin limits the accessibility of transcription factors and RNA polymerase to gene promoters. Thus, chromatin conformation plays an important role in gene expression (55).

Tailless nucleosomes have been used to investigate the role of histone tails $(78,79)$. Using tailless nucleosomes treated with trypsin to cleave off the core histone tail domains, it was reported that the histone tails participate in inter- or intra-nuclesomal interactions and play a significant role in regulating the accessibility of genomic DNA (79). Also, nucleosomes containing truncated $\mathrm{H} 3$ and/or truncated $\mathrm{H} 4$ were utilized to clarify the role of flexible tails of $\mathrm{H} 3$ and $\mathrm{H} 4$ histones. The $\mathrm{N}$-terminal regions of histone $\mathrm{H} 3$ and $\mathrm{H} 4$ were implicated in the intranucleosomal interactions by restricting the DNA breathing motion and compacting the nucleosome (78). Therefore, histone tail truncations by specific protease might increase DNA accessibility and generate open conformation of nucleosomes, leading to gene activation.

\section{Linking to histone eviction}

Histones are evicted at many promoters during gene activation to allow access to the transcription machinery $(80,81)$. It was also suggested that the entire nucleosome is at least sometimes disassembled and reassembled during the process of RNA polymerase passage (80).

As mentioned previously, Santos-Rosa et al. identified a histone $\mathrm{H} 3$ endopeptidase in S.cerevisiae, which cleaves the $\mathrm{H} 3 \mathrm{~N}$-terminal tail at the promoter sites of genes following the

A

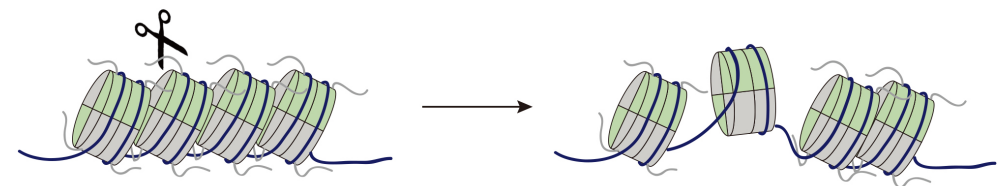

B

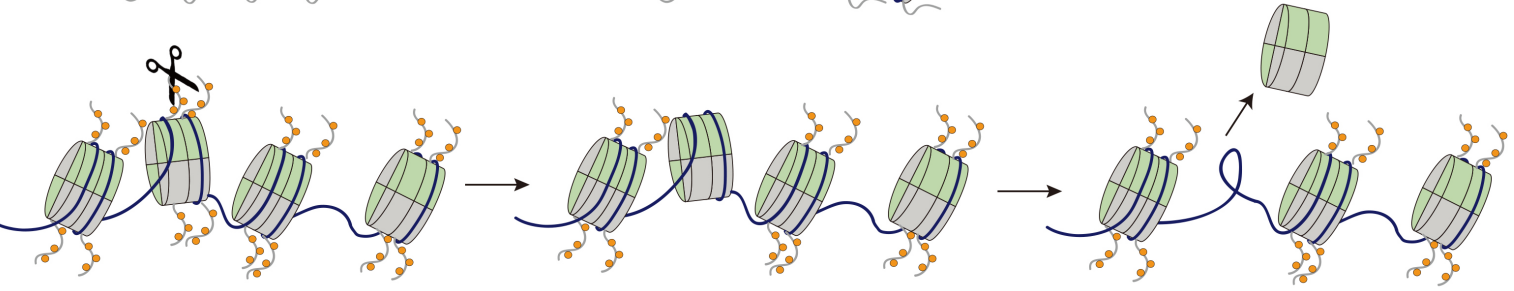

C

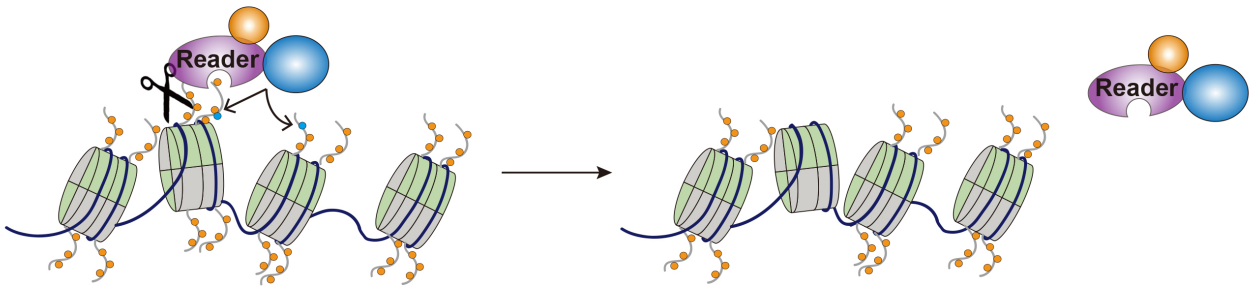

Fig. 1. Schematic model showing the functional roles of histone cleavage in gene expression. (A) Influence of genomic DNA or chromatin compaction on accessibility. Histone tail cleavages by protease might generate open chromatin structures and increase DNA accessibility for transcription factors, thereby contributing to gene activation. (B) Induction of histone eviction. The truncated histone by protease is unstable in the nucleosome. Histone tail cleavage may induce histone eviction, allowing easy access of transcription factors to DNA elements during gene activation. (C) Removal of PTMs and interacting proteins. Histone tail cleavage may lead to the radical removal of multiple modifications, resulting in blockage of the recruitment of effector proteins ("Reader" protein) or other PTM cascades on histone tails. 
induction of transcription (55). Notably, $\mathrm{H} 3$ clipping precedes the process of histone eviction, resulting in the localized clearing of repressive signals during the induction of gene expression. They suggested the possible role of a clipped H3 to mark the nucleosomes that are to be displaced prior to gene induction. Taken together with previous studies, histone tail cleavage may induce histone eviction, allowing easy access of transcription machinery to DNA during gene activation.

\section{Removal of PTMs and interacting proteins}

Diverse PTMs are found primarily on the tails of histones that extend distinctively from the nucleosome core, which is sensitive to proteases. To date, two characterized models have been used to consider the outcome of histone tail modifications. The first model suggests that histone tail modifications induce changes in the physical properties of the nucleosome that reduces inter- or intra-nucleosomal contacts, producing a more relaxed chromatin fiber. Of all known modifications, histone acetylation via the neutralization of the positive charge of lysine, and histone phosphorylation via the addition of negative charge, may cause decondensation of the chromatin structure (13). The second model suggests that modifications function as recognition marks to mediate the recruitment of effector proteins. Numerous chromatinassociated factors have been shown to specifically interact with modified histones through many distinct domains such as bromodomain, PHD finger, chromodomain, Tudor domain, PWWP domain, and MBT domain (62-64). These histone tail modifications are modulated by specific enzymes that add or remove modifications, respectively. Although specific modifications can be removed by specific enzymes, histone clipping may be an efficient way to erase multiple modifications of histone tails concurrently. That is, histone tail cleavage could cause the radical removal of multiple modifications, thereby blocking the recruitment of effector proteins or other PTM cascades on histone tails.

\section{PERSPECTIVES}

Although a growing body of studies has revealed histone tail cleavages in diverse cellular processes and identified specific proteases responsible for histone cleavages, these findings have raised many questions.

In particular, it would be interesting to determine the genes that are regulated by histone cleavage. Our integrated genome-wide analysis of ChIP-seq and RNA-seq data revealed that MMP-9 cleaved histone tails in approximately $8 \%$ of all protein-coding genes during osteoclastogenesis and many osteoclast-related genes were regulated (53). Additionally, JMJD5-mediated $\mathrm{H} 3$ tail clipping affected cell cycle-related gene transcription (56). However, the genes that are directly affected by protease-specific histone cleavage still need to be investigated.

It is also important to determine how proteases localize at specific genes under specific conditions. It is suggested that specific histone modifications could recruit histone proteases. We observed that H3K27me1 is necessary for the localization and function of MMP-9 at osteoclastogenic genes as a protease catalyzing $\mathrm{H} 3$ tail proteolysis (unpublished data). Alternatively, a crosstalk or interaction between proteases and other histone modifying enzymes might exist that enables histone proteases to localize at specific sites (30).

Finally, a way of controlling protease activity needs to be investigated. Protease can be post-translationally regulated. For example, the nuclear translocation of Cathepsin D was regulated by its post-translational modification, tyrosine nitration (71). Also, histone tail modifications affect the cleavage activity. It has been suggested that Cathepsin L cleavage activity might be modulated by covalent modifications such as H3K18ac or H3K27me2 (51). Moreover, CBP/p300-mediated acetylation of H3K18 facilitated MMP-9dependent H3 proteolysis (53). Nonetheless, it will be interesting to determine the upstream effectors that stimulate or inhibit protease activity in signaling pathways.

\section{ACKNOWLEDGEMENTS}

This work was supported by a grant from the National Research Foundation (NRF) of Korea (2015R1A4A1041869 and 2017R1C1B2008017 to K.K.; 2016R1A6A3A11935271 to S.J.Y.).

\section{CONFLICTS OF INTEREST}

The authors have no conflicting interests.

\section{REFERENCES}

1. Bentley GA, Lewit-Bentley A, Finch JT, Podjarny AD and Roth M (1984) Crystal structure of the nucleosome core particle at 16 A resolution. J Mol Biol 176, 55-75

2. Kornberg RD (1974) Chromatin structure: a repeating unit of histones and DNA. Science 184, 868-871

3. Kornberg RD and Lorch Y (1999) Twenty-five years of the nucleosome, fundamental particle of the eukaryote chromosome. Cell 98, 285-294

4. Kornberg RD and Thomas JO (1974) Chromatin structure; oligomers of the histones. Science 184, 865-868

5. Luger K, Mader AW, Richmond RK, Sargent DF and Richmond TJ (1997) Crystal structure of the nucleosome core particle at 2.8 A resolution. Nature 389, 251-260

6. Reeve JN, Sandman K and Daniels CJ (1997) Archaeal histones, nucleosomes, and transcription initiation. Cell 89, 999-1002

7. Allan J, Hartman PG, Crane-Robinson C and Aviles FX (1980) The structure of histone $\mathrm{H} 1$ and its location in chromatin. Nature 288, 675-679

8. Thomas JO (1999) Histone H1: location and role. Curr Opin Cell Biol 11, 312-317

9. Wolffe AP and Kurumizaka H (1998) The nucleosome: a 
powerful regulator of transcription. Prog Nucleic Acid Res Mol Biol 61, 379-422

10. Demeret C, Vassetzky Y and Mechali M (2001) Chromatin remodelling and DNA replication: from nucleosomes to loop domains. Oncogene 20, 3086-3093

11. Kornberg RD and Lorch $Y$ (1999) Chromatin-modifying and -remodeling complexes. Curr Opin Genet Dev 9, 148-151

12. Arnaudo AM and Garcia BA (2013) Proteomic characterization of novel histone post-translational modifications. Epigenetics Chromatin 6, 24

13. Bannister AJ and Kouzarides T (2011) Regulation of chromatin by histone modifications. Cell Res 21, 381-395

14. Beck HC, Nielsen EC, Matthiesen R et al (2006) Quantitative proteomic analysis of post-translational modifications of human histones. Mol Cell Proteomics 5, 1314-1325

15. Chen Y, Sprung R, Tang Y et al (2007) Lysine propionylation and butyrylation are novel post-translational modifications in histones. Mol Cell Proteomics 6, 812-819

16. Dai L, Peng C, Montellier E et al (2014) Lysine 2-hydroxyisobutyrylation is a widely distributed active histone mark. Nat Chem Biol 10, 365-370

17. Fierz B and Muir TW (2012) Chromatin as an expansive canvas for chemical biology. Nat Chem Biol 8, 417-427

18. Jenuwein $T$ and Allis CD (2001) Translating the histone code. Science 293, 1074-1080

19. Kouzarides T (2007) Chromatin modifications and their function. Cell 128, 693-705

20. Tan M, Luo $H$, Lee $S$ et al (2011) Identification of 67 histone marks and histone lysine crotonylation as a new type of histone modification. Cell 146, 1016-1028

21. Xie Z, Dai J, Dai L et al (2012) Lysine succinylation and lysine malonylation in histones. Mol Cell Proteomics 11, 100-107

22. Young NL, Dimaggio PA and Garcia BA (2010) The significance, development and progress of high-throughput combinatorial histone code analysis. Cell Mol Life Sci 67, 3983-4000

23. Shahbazian MD and Grunstein M (2007) Functions of site-specific histone acetylation and deacetylation. Annu Rev Biochem 76, 75-100

24. Lawrence M, Daujat S and Schneider R (2016) Lateral Thinking: How Histone Modifications Regulate Gene Expression. Trends Genet 32, 42-56

25. Strahl BD and Allis CD (2000) The language of covalent histone modifications. Nature 403, 41-45

26. Roadmap Epigenomics Consortium, Kundaje A, Meuleman W et al (2015) Integrative analysis of 111 reference human epigenomes. Nature 518, 317-330

27. Black JC, Van Rechem C and Whetstine JR (2012) Histone lysine methylation dynamics: establishment, regulation, and biological impact. Mol Cell 48, 491-507

28. Seto $E$ and Yoshida M (2014) Erasers of histone acetylation: the histone deacetylase enzymes. Cold Spring Harb Perspect Biol 6, a018713

29. Narlikar GJ, Sundaramoorthy R and Owen-Hughes T (2013) Mechanisms and functions of ATP-dependent chromatin-remodeling enzymes. Cell 154, 490-503

30. Azad GK and Tomar RS (2014) Proteolytic clipping of histone tails: the emerging role of histone proteases in regulation of various biological processes. Mol Biol Rep $41,2717-2730$

31. Dhaenens $M$, Glibert $P$, Meert $P$, Vossaert $L$ and Deforce D (2015) Histone proteolysis: a proposal for categorization into 'clipping' and 'degradation'. Bioessays 37, 70-79

32. Osley MA (2008) Epigenetics: how to lose a tail. Nature 456, 885-886

33. Zhou P, Wu E, Alam HB and Li Y (2014) Histone cleavage as a mechanism for epigenetic regulation: current insights and perspectives. Curr Mol Med 14, 1164-1172

34. Phillips DM and Johns EW (1959) A study of the proteinase content and the chromatography of thymus histones. Biochem J 72, 538-544

35. Eickbush TH, Watson DK and Moudrianakis EN (1976) A chromatin-bound proteolytic activity with unique specificity for histone H2A. Cell 9, 785-792

36. Gorovsky MA and Keevert JB (1975) Absence of histone F1 in a mitotically dividing, genetically inactive nucleus. Proc Natl Acad Sci U S A 72, 2672-2676

37. Eickbush TH, Godfrey JE, Elia MC and Moudrianakis EN (1988) H2a-specific proteolysis as a unique probe in the analysis of the histone octamer. J Biol Chem 263, 18972-18978

38. Watson DK and Moudrianakis EN (1982) Histonedependent reconstitution and nucleosomal localization of a nonhistone chromosomal protein: the H2A-specific protease. Biochemistry 21, 248-256

39. Okawa $\mathrm{Y}$, Takada K, Minami J, Aoki K, Shibayama $\mathrm{H}$ and Ohkawa K (2003) Purification of N-terminally truncated histone H2A-monoubiquitin conjugates from leukemic cell nuclei: probable proteolytic products of ubiquitinated H2A. Int J Biochem Cell Biol 35, 1588-1600

40. Pantazis P, Sarin PS and Gallo RC (1981) Detection of the histone-2A related polypeptide in differentiated human myeloid cells (HL-60) and its distribution in human acute leukemia. Int J Cancer 27, 585-592

41. Simpkins $\mathrm{H}$ and Mahon K (1977) The histone content of chromatin preparations from leukaemic cells. $\mathrm{Br}$ J Haematol 37, 467-473

42. Glibert P, Vossaert L, Van Steendam K et al (2014) Quantitative proteomics to characterize specific histone $\mathrm{H} 2 \mathrm{~A}$ proteolysis in chronic lymphocytic leukemia and the myeloid THP-1 cell line. Int J Mol Sci 15, 9407-9421

43. Minami J, Takada K, Aoki K et al (2007) Purification and characterization of C-terminal truncated forms of histone $\mathrm{H} 2 \mathrm{~A}$ in monocytic THP-1 cells. Int J Biochem Cell Biol 39, $171-180$

44. Dhaenens M, Glibert P, Lambrecht S et al (2014) Neutrophil Elastase in the capacity of the "H2A-specific protease". Int J Biochem Cell Biol 51, 39-44

45. Papayannopoulos V, Metzler KD, Hakkim A and Zychlinsky A (2010) Neutrophil elastase and myeloperoxidase regulate the formation of neutrophil extracellular traps. J Cell Biol 191, 677-691

46. Vogler C, Huber C, Waldmann T et al (2010) Histone $\mathrm{H} 2 \mathrm{~A}$ C-terminus regulates chromatin dynamics, remodeling, and histone $\mathrm{H} 1$ binding. PLoS Genet 6, e1001234

47. Panda P, Chaturvedi MM, Panda AK, Suar M and Purohit 
JS (2013) Purification and characterization of a novel histone $\mathrm{H} 2 \mathrm{~A}$ specific protease ( $\mathrm{H} 2 \mathrm{Asp}$ ) from chicken liver nuclear extract. Gene 512, 47-54

48. Melo FR, Vita F, Berent-Maoz B, Levi-Schaffer F, Zabucchi G and Pejler G (2014) Proteolytic histone modification by mast cell tryptase, a serglycin proteoglycan-dependent secretory granule protease. J Biol Chem 289, 7682-7690

49. Melo FR, Wallerman O, Paivandy A et al (2017) Tryptase-catalyzed core histone truncation: A novel epigenetic regulatory mechanism in mast cells. J Allergy Clin Immunol 140, 474-485

50. Duarte LF, Young AR, Wang Z et al (2014) Histone H3.3 and its proteolytically processed form drive a cellular senescence programme. Nat Commun 5, 5210

51. Duncan EM, Muratore-Schroeder TL, Cook RG et al (2008) Cathepsin L proteolytically processes histone H3 during mouse embryonic stem cell differentiation. Cell 135, 284-294

52. Grigera PR and Tisminetzky SG (1984) Histone H3 modification in BHK cells infected with foot-and-mouth disease virus. Virology 136, 10-19

53. Kim K, Punj V, Kim JM et al (2016) MMP-9 facilitates selective proteolysis of the histone $\mathrm{H} 3$ tail at genes necessary for proficient osteoclastogenesis. Genes Dev 30, 208-219

54. Mahendra G and Kanungo MS (2000) Age-related and steroid induced changes in the histones of the quail liver. Arch Gerontol Geriatr 30, 109-114

55. Santos-Rosa H, Kirmizis A, Nelson C et al (2009) Histone $\mathrm{H} 3$ tail clipping regulates gene expression. Nat Struct Mol Biol 16, 17-22

56. Shen J, Xiang X, Chen L et al (2017) JMJD5 cleaves monomethylated histone $\mathrm{H} 3 \mathrm{~N}$-tail under DNA damaging stress. EMBO Rep 18, 2131-2143

57. Mandal P, Azad GK and Tomar RS (2012) Identification of a novel histone $\mathrm{H} 3$ specific protease activity in nuclei of chicken liver. Biochem Biophys Res Commun 421, 261-267

58. Mandal P, Verma N, Chauhan S and Tomar RS (2013) Unexpected histone $\mathrm{H} 3$ tail-clipping activity of glutamate dehydrogenase. J Biol Chem 288, 18743-18757

59. Vossaert L, Meert P, Scheerlinck E et al (2014) Identification of histone $\mathrm{H} 3$ clipping activity in human embryonic stem cells. Stem Cell Res 13, 123-134

60. Allis CD, Bowen JK, Abraham GN, Glover CV and Gorovsky MA (1980) Proteolytic processing of histone H3 in chromatin: a physiologically regulated event in Tetrahymena micronuclei. Cell 20, 55-64

61. Falk MM, Grigera PR, Bergmann IE, Zibert A, Multhaup G and Beck E (1990) Foot-and-mouth disease virus protease 3C induces specific proteolytic cleavage of host cell histone H3. J Virol 64, 748-756

62. Tesar M and Marquardt O (1990) Foot-and-mouth disease virus protease $3 \mathrm{C}$ inhibits cellular transcription and mediates cleavage of histone H3. Virology 174, 364-374

63. Sudhan DR and Siemann DW (2015) Cathepsin L targeting in cancer treatment. Pharmacol Ther 155, 105-116

64. Turk V, Stoka V, Vasiljeva O et al (2012) Cysteine cathepsins: from structure, function and regulation to new frontiers. Biochim Biophys Acta 1824, 68-88

65. Goulet B, Baruch A, Moon NS et al (2004) A cathepsin L isoform that is devoid of a signal peptide localizes to the nucleus in $\mathrm{S}$ phase and processes the CDP/Cux transcription factor. Mol Cell 14, 207-219

66. Goulet B, Sansregret L, Leduy L et al (2007) Increased expression and activity of nuclear cathepsin $\mathrm{L}$ in cancer cells suggests a novel mechanism of cell transformation. Mol Cancer Res 5, 899-907

67. Goulet B, Truscott M and Nepveu A (2006) A novel proteolytically processed CDP/Cux isoform of $90 \mathrm{kDa}$ is generated by cathepsin L. Biol Chem 387, 1285-1293

68. Grotsky DA, Gonzalez-Suarez I, Novell A et al (2013) BRCA1 loss activates cathepsin L-mediated degradation of 53BP1 in breast cancer cells. J Cell Biol 200, 187-202

69. Xue Y, Vashisht AA, Tan Y, Su T and Wohlschlegel JA (2014) PRB1 is required for clipping of the histone $\mathrm{H} 3 \mathrm{~N}$ terminal tail in Saccharomyces cerevisiae. PLoS One 9, e90496

70. Mishra RN and Kanungo MS (1994) Alterations in histones of the liver and oviduct of Japanese quail during aging. Mol Biol Rep 20, 15-18

71. Khalkhali-Ellis Z, Goossens W, Margaryan NV and Hendrix MJ (2014) Cleavage of Histone 3 by Cathepsin D in the involuting mammary gland. PLoS One 9, e103230

72. Fanjul-Fernandez $M$, Folgueras $A R$, Cabrera $S$ and Lopez-Otin C (2010) Matrix metalloproteinases: evolution, gene regulation and functional analysis in mouse models. Biochim Biophys Acta 1803, 3-19

73. Nagase H, Visse R and Murphy G (2006) Structure and function of matrix metalloproteinases and TIMPs. Cardiovasc Res 69, 562-573

74. Xie Y, Mustafa A, Yerzhan A et al (2017) Nuclear matrix metalloproteinases: functions resemble the evolution from the intracellular to the extracellular compartment. Cell Death Discov 3, 17036

75. Allis CD, Allen RL, Wiggins JC, Chicoine LG and Richman R (1984) Proteolytic processing of h1-like histones in chromatin: a physiologically and developmentally regulated event in Tetrahymena micronuclei. J Cell Biol 99, 1669-1677

76. Lee PY, Park BC, Chi SW et al (2016) Histone H4 is cleaved by granzyme A during staurosporine-induced cell death in B-lymphoid Raji cells. BMB Rep 49, 560-565

77. Lin R, Cook RG and Allis CD (1991) Proteolytic removal of core histone amino termini and dephosphorylation of histone $\mathrm{H} 1$ correlate with the formation of condensed chromatin and transcriptional silencing during Tetrahymena macronuclear development. Genes Dev 5, 1601-1610

78. Nurse NP, Jimenez-Useche I, Smith IT and Yuan C (2013) Clipping of flexible tails of histones $\mathrm{H} 3$ and $\mathrm{H} 4$ affects the structure and dynamics of the nucleosome. Biophys J 104, 1081-1088

79. Polach KJ, Lowary PT and Widom J (2000) Effects of core histone tail domains on the equilibrium constants for dynamic DNA site accessibility in nucleosomes. J Mol Biol 298, 211-223

80. Das C and Tyler JK (2013) Histone exchange and histone modifications during transcription and aging. Biochim Biophys Acta 1819, 332-342

81. Lee CK, Shibata Y, Rao B, Strahl BD and Lieb JD (2004) Evidence for nucleosome depletion at active regulatory regions genome-wide. Nat Genet 36, 900-905 